\title{
\begin{tabular}{l|l} 
Mibraries & DSpace@MIT
\end{tabular}
}

\author{
MIT Open Access Articles
}

Biochar mines: Panacea to climate change and energy crisis?

The MIT Faculty has made this article openly available. Please share how this access benefits you. Your story matters.

Citation: Thengane, Sonal K. and Santanu Bandyopadhyay. "Biochar mines: Panacea to climate change and energy crisis?" Clean Technologies and Environmental Policy 22, 1 (December 2019): 5-10 ( 2019 Springer-Verlag

As Published: https://doi.org/10.1007/s10098-019-01790-1

Publisher: Springer Science and Business Media LLC

Persistent URL: https://hdl.handle.net/1721.1/128379

Version: Author's final manuscript: final author's manuscript post peer review, without publisher's formatting or copy editing

Terms of Use: Article is made available in accordance with the publisher's policy and may be subject to US copyright law. Please refer to the publisher's site for terms of use. 


\section{Biochar mines: Panacea to climate change and energy crisis?}

Cite this article as: Sonal K. Thengane and Santanu Bandyopadhyay, Biochar mines: Panacea to climate change and energy crisis?, Clean Technologies and Environmental Policy https://doi.org/10.1007/s10098-019-01790-1

This Author Accepted Manuscript is a PDF file of an unedited peer-reviewed manuscript that has been accepted for publication but has not been copyedited or corrected. The official version of record that is published in the journal is kept up to date and so may therefore differ from this version.

Terms of use and reuse: academic research for non-commercial purposes, see here for full terms. https://www.springer.com/aam-terms-v1 


\title{
Biochar Mines: Panacea to Climate Change and Energy Crisis?
}

\author{
Sonal K. Thengane \\ Department of Mechanical Engineering, \\ Massachusetts Institute of Technology, \\ Cambridge MA 02139, USA
}

and

Santanu Bandyopadhyay*

Department of Energy Science and Engineering,

Indian Institute of Technology Bombay,

Powai, Mumbai 400076, India

*Corresponding author. Tel.: +91 22 25767894; Fax: +91 2225726875.

E-mail address: santanub@iitb.ac.in (S. Bandyopadhyay) 


\begin{abstract}
Negative emission technology such as bioenergy with carbon capture and storage is extremely important to offset the presence of atmospheric greenhouse gases. Biochar, a solid product obtained from the thermal decomposition of biomass, is a promising pathway for the storage of solid carbon and energy applications. This article proposes the concept of artificial biochar mines as an encouraging negative emission technology through basic techno-economic analysis. Torrefaction at small to medium scale proves to be the preferred process for production of biochar from residual biomass with the $\mathrm{CO}_{2}$ sequestration cost in the range of $43-47 \$ /$. Benefits of the artificial biochar mine include negative emission with positive energy output, residual biomass management, low risk, less storage space, easy site selection, potentially beneficial applications, economically encouraging, and future energy security.
\end{abstract}

Keywords: biochar mine; negative emission technologies; climate change; techno-economic analysis; energy security

\title{
Negative Emission Technologies
}

Carbon dioxide $\left(\mathrm{CO}_{2}\right)$, generated primarily from the oxidation of carbon-intensive fossil fuels directly or indirectly, is the most important linkage with the issues of climate change. At present, emissions of $\mathrm{CO}_{2}$ and other greenhouse gases (GHG) are the highest in the history of humankind. To achieve the target of limiting average global temperature rise within 1.5 to $2{ }^{\circ} \mathrm{C}$ by 2100 , three essential steps have to be taken on urgent basis: (i) reduce overall energy demand through energy management and conservations; (ii) increase renewable energy sources such as solar, hydro, wind, biomass, or geothermal as an alternative to fossil fuels; and (iii) offset positive GHG emissions from existing technologies with negative emissions technologies (NETs). NETs may help in removing atmospheric $\mathrm{CO}_{2}$ directly or indirectly from existing processes through retrofits. Negative emissions not only accounts for natural processes but also the intentional human efforts to remove $\mathrm{CO}_{2}$ emissions from the atmosphere (Minx et al. 2018). Carbon capture and storage (CCS) systems are being promoted in government and research analysis all over the world as a promising NET. Other than CCS, the common processes and technologies falling 
under the category of NETs include afforestation and reforestation, soil carbon sequestration, ocean fertilization, biochar, enhanced rock weathering, bioenergy with carbon capture and storage.

Bioenergy with carbon capture and storage (bio-CCS) is seen as one of the most promising NETs by a majority of climate scientists. Carbon being the second-most abundant element (after oxygen) in the biosphere of the earth, it provides a basis for the storage for renewable energy in the form of biomass through photosynthesis. On a dry carbon basis, the global annual biomass production is more than 200 billion tons (Bar-On et al. 2018). Figure 1 shows the net carbon balance for different energy alternatives including fossil fuels, renewables, and bio-energy. Biomass or phytomass, in particular, has a significant potential for a sustainable future through various processes and applications (Mardoyan and Braun 2015). Amongst the applications, power generation and thermal applications have been at the forefront, whereas amongst the processes, gasification, pyrolysis, and combustion have been explored widely. Figure 2 compares the average carbon balance for different processes of biomass conversion. The process of combustion releases highest percentage of carbon in biomass to the atmosphere, whereas the processes of torrefaction ( $80 \%$ less) and pyrolysis (50\% less) release lowest percentage of carbon back to the atmosphere. Integrating torrefaction and pyrolysis of sustainably grown biomass with CCS appears to be most promising NET. For conventional CCS system, the terrestrial sinks for storing $\mathrm{CO}_{2}$ are limited by the geographical availability of appropriate sites. Furthermore, difficulties in handling gaseous $\mathrm{CO}_{2}$ and the risk of leakage limit its attractiveness. Biochar produced from biomass can offer a long-lasting carbon sink by permanently storing it in the ground to create biochar mines. The primary objective of this perspective is to propose the idea of creating artificial biochar mines that are technically feasible, economically viable, and capable of resolving the issues of climate change and energy security. 


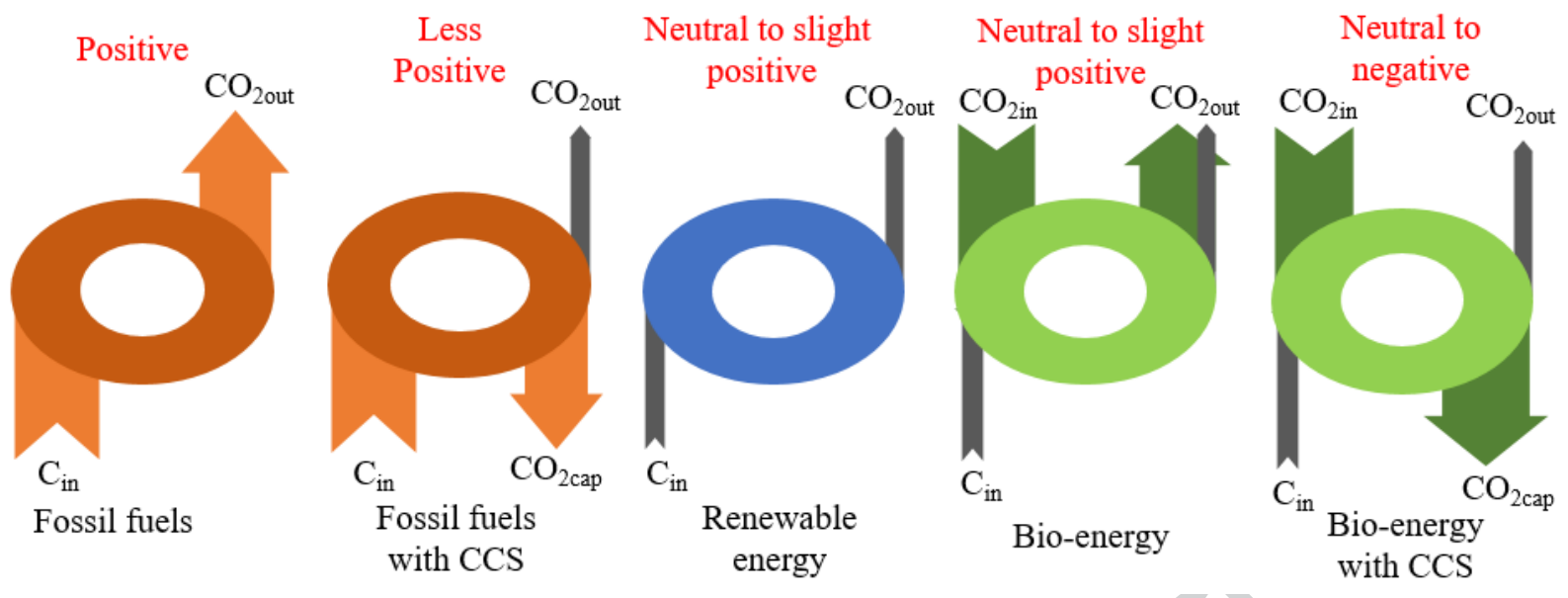

Figure 1. Carbon balance for different energy alternatives

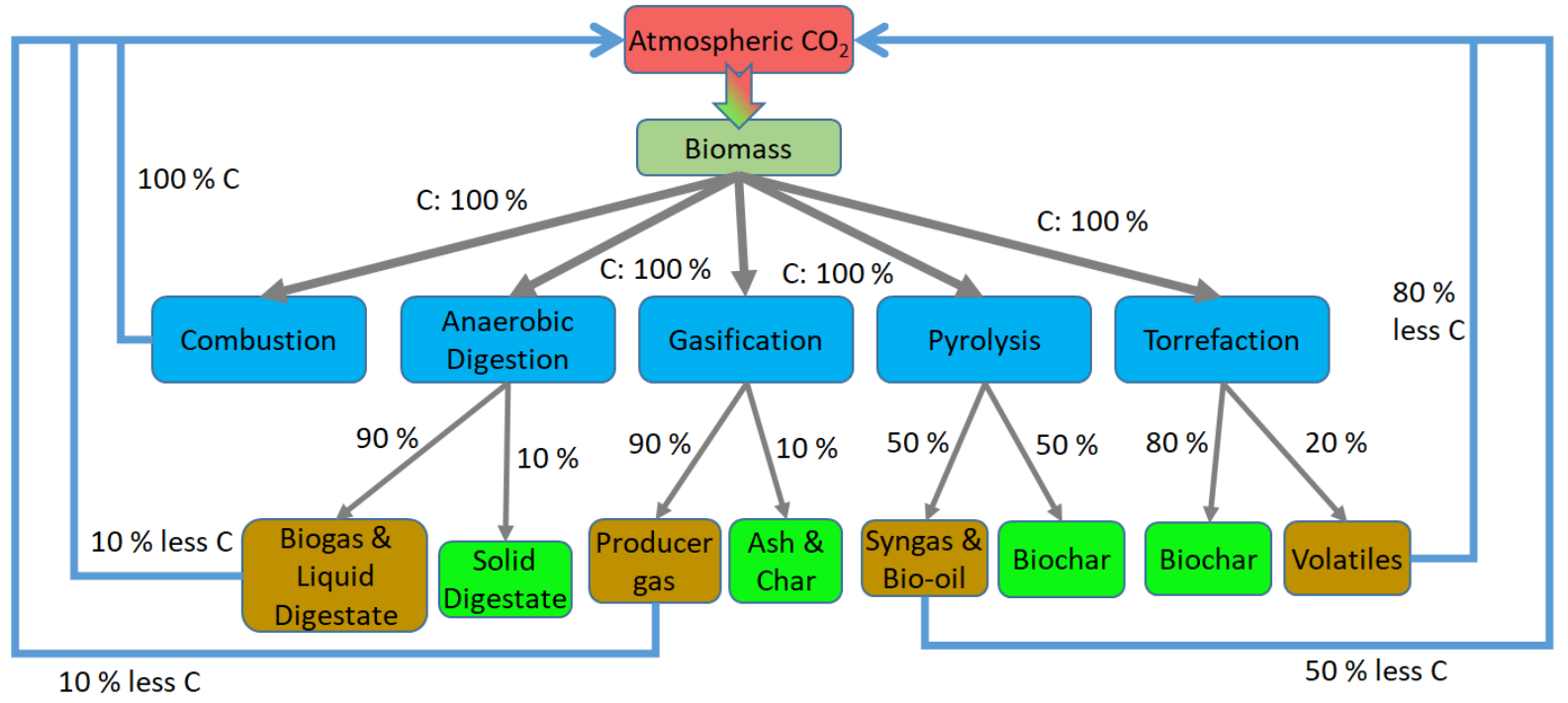

Figure 2. Carbon balance for different processes of biomass conversion

\section{Sequestrating Biochar}

Biochar, also known as bio-coal or bio-carbon, is a solid product obtained from the thermal decomposition of biomass at a wide range of temperatures (usually $200-900^{\circ} \mathrm{C}$ ) in an inert or a partial oxidative environment. The process is primarily known as pyrolysis. Based on the operating conditions (viz., heating rate, temperature range, and gaseous medium), it can be further classified as slow, mild (torrefaction), or fast pyrolysis. Pyrolysis also yields liquid and 
gaseous products in addition to solid biochar. In most of the existing pyrolysis systems, the liquid and gaseous products are combusted to produce thermal and electrical energy.

Figure 2 suggests that the torrefaction of biomass, with the maximum potential for biochar production, is a promising pathway for the storage of solid carbon and energy applications. Figure 3 compares the biochar production processes through pyrolysis and torrefaction of biomass. Torrefaction is a thermochemical treatment of biomass at 200 to $300^{\circ} \mathrm{C}$ under atmospheric pressure, often in the partial or complete absence of oxygen (Basu 2018). The process removes the moisture and partially decomposes the lignocellulosic components liberating some volatiles, leaving behind a final solid product referred to as 'torrefied biomass' or simply biochar (Lipinsky et al. 2002). Figure 4 shows the mass and energy balance and the improvement in biomass properties for a typical torrefaction unit. In the biochar production process, the fixed $\mathrm{CO}_{2}$ is bound to the carbon matrix of biochar. Thus, biochar production provides an efficient way to remove $\mathrm{CO}_{2}$ from the atmospheric carbon cycle and to remit the global warming. Storage of solid biochar could serve as a permanent carbon-sequestration mechanism.

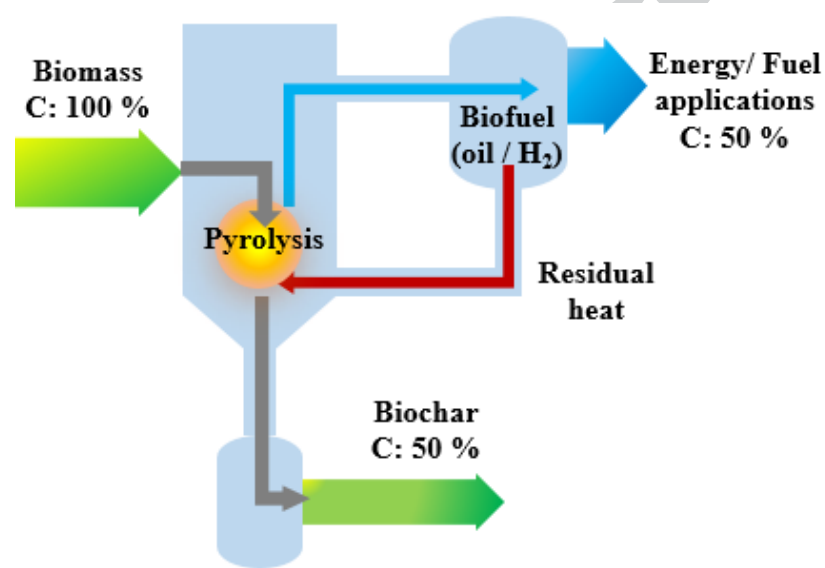

(a)

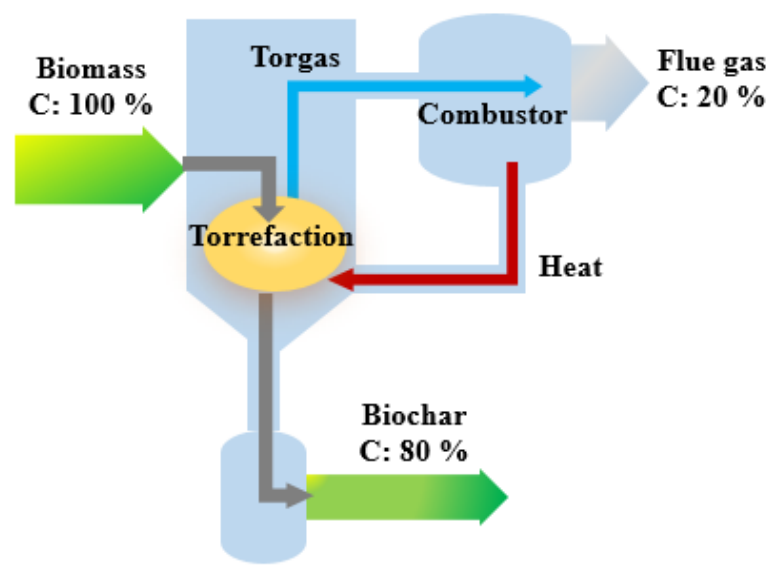

(b)

Figure 3. Biochar production processes: (a) Pyrolysis; (b) Torrefaction 


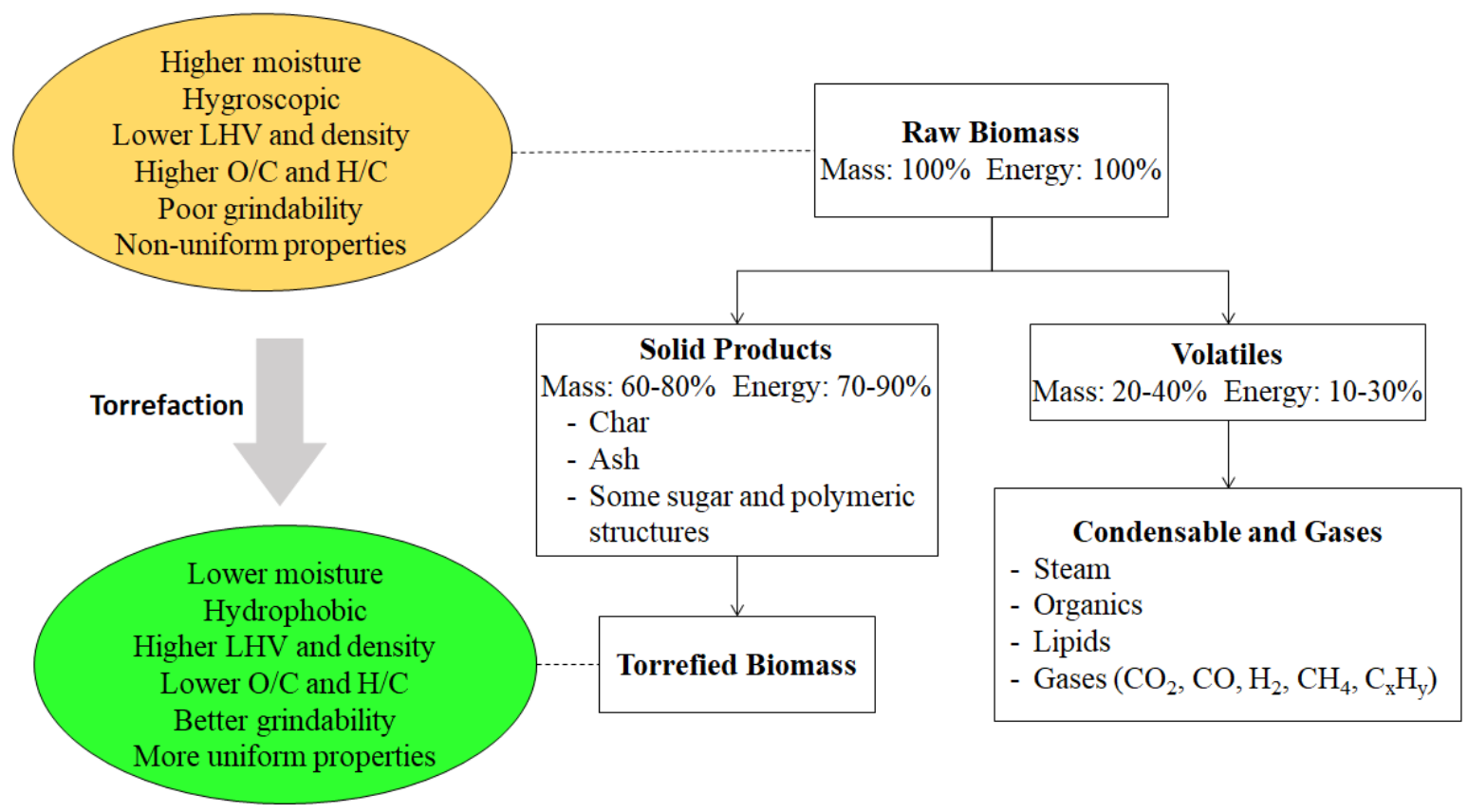

Figure 4. Mass and energy balance for a typical biomass torrefaction unit

Figure 5 depicts different possible applications of biochar in diverse sectors, including energy, sustainability, and climate change. Recent studies have also acknowledged fascinating applications of biochar-based materials in energy storage and conversion because of their easily tuned surface chemistry and porosity (Liu et al. 2019). Appropriate biochar can enhance plant growth, retain nutrients, provide habitat for microorganisms, improve soil water holding capacity, soil water availability, and hydraulic conductivity (Mohan et al. 2018), also making it the desired remedy for reclamation of most mining sites (Fellet et al. 2011). This led to the concept of employing of biochar as an agent for bio-sequestration of carbon through soil amendment (Wijitkosum and Sriburi 2016). Tan et al. (2018) proposed a pinch analysis-based approach for planning biochar-based carbon management networks. By reducing nitrous oxide emissions from certain fertilizers, biochar-amended soils indirectly reduce more potent GHG emission of nitrous oxide. The use of residual biomass for biochar production also resolves waste management and otherwise resulting air pollution issues. 


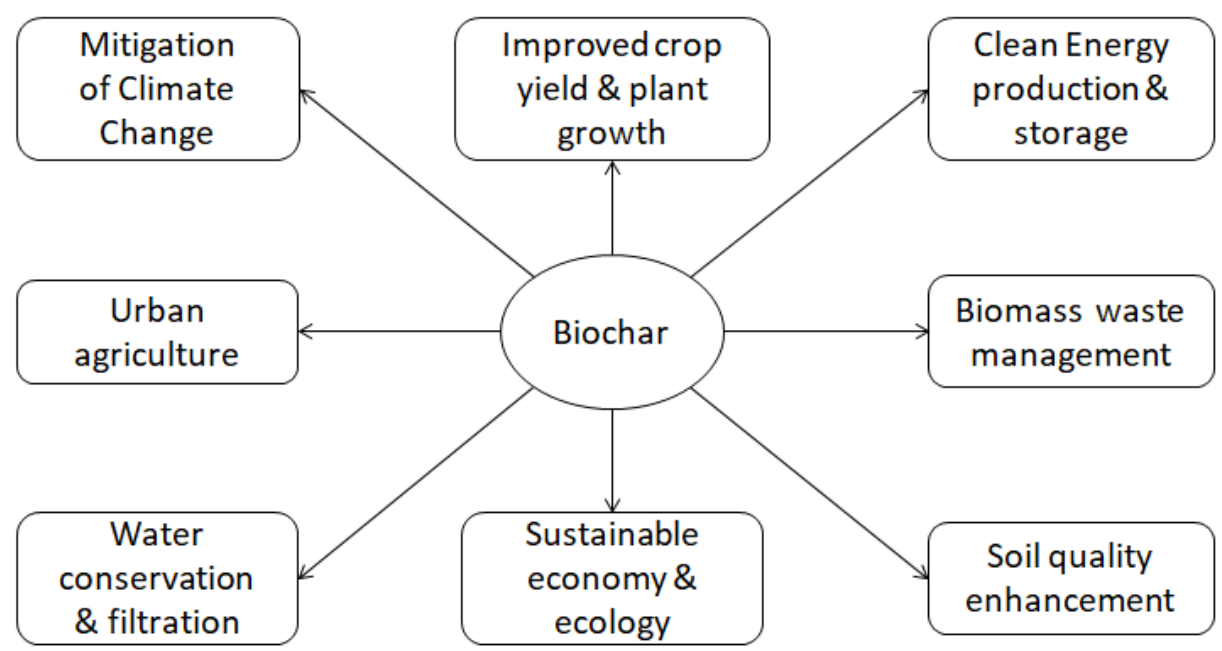

Figure 5. Applications of biochar in different sectors

Other than using biochar in the soil, it can be stored in the solid form in any underground space such as unused mines, or simply dumped under barren land to create artificial biochar mines. The risk of carbon coming back to the atmosphere is extremely low. In general, biochar is not completely degradable by microbes. Discoveries of biochar particles in Terra Preta soils at Acutuba site in Amazonia and Jaguariuna soil site in Brazil, confirm that biochar materials could be stored in soils as a means of carbon sequestration for hundreds and perhaps thousands of years (Lee et al. 2010). In a recent study, the net storage realized in the first 200 years was found insensitive to biochar decomposition rates, which is often at least 10 times slower than original feedstock decomposition rate (Campbell et al. 2018). These findings further support the idea of storing biochar in artificial underground mines for energy purposes, especially if the motivation is to utilize it beyond a century. The time frame of a century may be sufficient to mitigate the atmospheric $\mathrm{CO}_{2}$ emissions substantially, which otherwise would have emitted right after utilization of biomass or during decomposition. Though residual biomass from farms, forests, carpentry, municipal areas, mills, and factories should be preferred for biochar production, sometimes even growing biomass such as bamboo or switchgrass for the same may prove to be economical. Live biomass continuously captures $\mathrm{CO}_{2}$ from the atmosphere and need good quality soil for higher yields. The best scenario can be identifying a site to grow appropriate biomass, set-up a biochar production facility, use part of biochar for growing biomass and store remaining part layer-wise at same site. Another alternative is having the biochar production and 
storage facility close to the sources of residual biomass. Since this site has significant amount of biochar after a while, it can be referred to as biochar mine just like a coal mine. However, unlike coal mines, extracting biochar from these artificial mines for energy purposes would be much easier and economical without any cost involving its discovery. Furthermore, depending on the process of converting biomass to biochar, significant amount of surplus energy can be generated which can be used for various applications. The economic breakeven point for operating a specific biochar mine can be determined by the revenue generated from waste management, energy from liquid and gaseous fuels, other specialty crops grown on-site, and sale of a portion of biochar. These biochar mines may provide additional energy security. In rare cases, if the biochar stored underground is not put to use for energy purposes within next 200 years, there are multiple alternatives. The site could be used for growing high-value crops, or the biochar could be extracted for other applications such as making activated carbon, carbon black, or for soil amenders. In either case, sustainable biomass production, coupled with biochar production and creation of biochar mines, can be the most crucial NET.

\section{Techno-economic feasibility}

The preliminary economic analysis predicts the average cost of biochar production in the range of 100-300 \$/ton depending on quality and production technology (US Biochar Initiative 2018). Some studies have estimated the production costs even up to $500 \$ /$ ton based on the application rate of 10-70 ton/hectare, and found the option of biochar production from residual biomass (e.g. agro-residues) at application site as most promising (Maroušek 2014; Vochozka et al. 2016; Hašková 2017;). A recent study also proposed on-farm biochar production followed by on-farm use and nutrient recycling as the most economical alternative in the long term, in contrast to using it for energy applications for short term profit (Maroušek et al. 2019). The calorific value of torrefied biomass or biochar for most of the woods and agro-residue falls in the range of 20-30 $\mathrm{MJ} / \mathrm{kg}$, making it a potential feedstock for co-firing with coal or as a solid fuel for thermal applications. The mitigation costs for the fossil fuel-based power plant with conventional CCS are expected to lower if part of it is replaced by biomass, biochar or other renewable sources. David and Herzog (2010) had calculated the mitigation costs as $49 \$$ per ton of $\mathrm{CO}_{2}$ for capture in 
natural gas combined cycle (NGCC) plant and $121 \$$ per ton for a capture in integrated gasification combined cycle (IGCC) power plant. The utilization of biochar for CCS would be justified only if the total mitigation costs are well below the fossil-based plants equipped with conventional CCS.

Table 1 shows the cost calculations for $\mathrm{CO}_{2}$ sequestration using biochar from two different technologies of pyrolysis and torrefaction at two different scales. The data for torrefaction technology is assumed based on the technical potential of the process (Kung et al. 2019; Stępień et al. 2019) and the costs provided by an upcoming start-up in the United States. The cost calculations are presented primarily for a biomass conversion facility on an annual basis and not for a typical biochar mine site. Biomass supplied is assumed to have moisture content (MC) of $40 \%$. The carbon sequestration cost is obtained by subtracting the value of biochar benefits and co-products (e.g. in terms of heat production potential) from the total cost of biochar production. However, the calculations presented here assumes that all of the produced biochar is used for sequestration, and does not account for the price of biochar as a product as well as value associated with carbon credits or crop yield or gaseous and liquid byproducts. For both processes, biochar is assumed to contain $79 \%$ carbon, and $97 \%$ of that is assumed to retain in biochar with $3 \%$ being lost as volatiles during storage (Timmons et al. 2017). Application cost mainly involves labor and diesel consumed during mixing biochar in soil or putting it underground. The cost of $\mathrm{CO}_{2}$ sequestration using the biochar approach falls in the range of 80$95 \$ /$ ton for pyrolysis and 40-50 \$/ton for torrefaction. This is mainly due to the higher yield of biochar with higher carbon content in case of torrefaction, which often takes place at lower temperatures $\left(200-350^{\circ} \mathrm{C}\right)$ compared to pyrolysis $\left(450-700^{\circ} \mathrm{C}\right)$. Other contributing factors are the lower capital and operating costs due to non-requirement of oil and gas separating units, relatively less utilities, air as medium, and significantly low energy requirement. 
Table 1. Cost calculations for $\mathrm{CO}_{2}$ sequestration using biochar from two different technologies Pyrolysis (Timmons Torrefaction et al. 2017)

\begin{tabular}{lllll}
\hline Plant Size (input t/day, 40 \% MC) & 10 & 100 & 10 & 100 \\
\hline Biomass t/y with 40 \% MC & 3300 & 33,000 & 3300 & 33,000 \\
\hline Plant Capital Cost (\$) & 558,000 & 3500,000 & 150,000 & 1014,124 \\
\hline Annualized Total Biomass Cost (\$) & 72,500 & 832,500 & 72,500 & 832,500 \\
\hline Annualized Total Plant Operating Costs (\$) & 87,900 & 667,380 & 67,500 & 543,086 \\
\hline Annualized Total Heat Value (\$) & 53,519 & 642,233 & 22,692 & 272,307 \\
\hline Net Annual Cost (\$) & 172,423 & 1268,756 & 134,927 & 1222,398 \\
\hline Biochar Yield on dry basis (\%) & 30 & 25 & 48 & 40 \\
\hline Annual biochar production (t) & 594 & 5009 & 950 & 8015 \\
\hline Biochar production cost per ton (\$) & 290 & 253 & 142 & 153 \\
\hline Carbon sequestered per ton biochar (\%) & 77 & 77 & 77 & 77 \\
\hline Cost of application of biochar per ton (\$) & 30 & 30 & 30 & 30 \\
\hline Cost of sequestration per ton Carbon (\$) & 353 & 304 & 159 & 173 \\
\hline Cost of sequestration per ton CO $(\$)$ & 96 & 83 & 43 & 47 \\
\hline
\end{tabular}

\section{Concluding remarks}

The concept of artificial biochar mines can contribute significantly to resolve issues of the energy crisis, along with mitigating climate change in a more beneficial manner compared to fossil fuel-based plants with conventional CCS. The use of residual biomass as feedstock for making biochar resolve the issue of biomass waste management and provide more employment opportunities, especially in the rural area. The technology of biomass conversion, availability of local and sustainable biomass, the distance between the location of biochar producing facilities and the sites of application or storage, etc. have a substantial influence on the techno-economic feasibility of the entire concept. The idea of developing biochar mines can overcome these limitations by having all the stages at a single site. For countries such as India and China having enormous agricultural land, mines, and workforce, there is a considerable scope to develop these 
biochar mines at mass scale without competing with the land use for other purposes. Additionally, these artificial biochar mines provide much-needed energy security in a costeffective manner. Major advantages of an artificial biochar mine are:

- Negative emissions with net positive energy output,

- Contributions towards residual biomass management,

- Low risk with lower storage space requirement as well as easier site selection,

- Potentially beneficial applications with added energy security for the future, and

- Economically favorable.

The implementation of the proposed approach may need to address the challenges concerning site selection, perennial operation, biomass availability and heterogeneity, and storage safety. Though the advances in the production of biochar from residual biomass are expected to reduce the production costs, the reliable and safe storage of biochar may incur additional costs. Hence, a detail techno-enviro-economic assessment of the concept in different topographical contexts will be the next step prior to field demonstration. In this era of increasingly stringent environmental standards and GHG limits, the carbon-neutral and renewable nature of biomass feedstock, along with the potential of long term $\mathrm{CO}_{2}$ sequestration presents the biochar mine as extremely attractive. Can it be the real panacea to the alarming issues of climate change and energy crisis?

\section{References}

Bar-On, Y.M., Phillips, R. and Milo, R., 2018. The biomass distribution on Earth. Proceedings of the National Academy of Sciences, 115(25), pp.6506-6511.

Basu, P., 2018. Biomass gasification, pyrolysis and torrefaction: practical design and theory. Third Ed. San Diego, Academic press.

Campbell, J.L., Sessions, J., Smith, D. and Trippe, K., 2018. Potential carbon storage in biochar made from logging residue: Basic principles and Southern Oregon case studies. PloS one, 13(9), p.e0203475.

David, J. and Herzog, H., 2000, August. The cost of carbon capture. In fifth international conference on greenhouse gas control technologies, Cairns, Australia (pp. 13-16).

Fellet, G., Marchiol, L., Delle Vedove, G. and Peressotti, A., 2011. Application of biochar on mine tailings: effects and perspectives for land reclamation. Chemosphere, 83(9), pp.12621267. 
Hašková, S., 2017. Holistic assessment and ethical disputation on a new trend in solid biofuels. Science and engineering ethics, 23(2), pp.509-519.

Kung, K.S., Shanbhogue, S., Slocum, A.H. and Ghoniem, A.F., 2019. A decentralized biomass torrefaction reactor concept. Part I: Multi-scale analysis and initial experimental validation. Biomass and Bioenergy, 125, pp.196-203.

Lee, J.W., Hawkins, B., Day, D.M. and Reicosky, D.C., 2010. Sustainability: the capacity of smokeless biomass pyrolysis for energy production, global carbon capture and sequestration. Energy \& environmental science, 3(11), pp.1695-1705.

Lipinsky, E.S., Arcate, J.R. and Reed, T.B., 2002. Enhanced wood fuels via torrefaction. Fuel Chemistry division preprints, 47(1), pp.408-410.

Liu, W.J., Jiang, H. and Yu, H.Q., 2019. Emerging applications of biochar-based materials for energy storage and conversion. Energy \& Environmental Science, 12, pp.1751-1779.

Mardoyan, A. and Braun, P., 2015. Analysis of Czech subsidies for solid biofuels. International Journal of Green Energy, 12(4), pp.405-408.

Maroušek, J., 2014. Significant breakthrough in biochar cost reduction. Clean Technologies and Environmental Policy, 16(8), pp.1821-1825.

Maroušek, J., Strunecký, O. and Stehel, V., 2019. Biochar farming: defining economically perspective applications. Clean Technologies and Environmental Policy, 21, pp.13891395.

Minx, J.C., Lamb, W.F., Callaghan, M.W., Fuss, S., Hilaire, J., Creutzig, F., Amann, T., Beringer, T., de Oliveira Garcia, W., Hartmann, J. and Khanna, T., 2018. Negative emissions-Part 1: Research landscape and synthesis. Environmental Research Letters, 13(6), p.063001.

Mohan, D., Abhishek, K., Sarswat, A., Patel, M., Singh, P. and Pittman, C.U., 2018. Biochar production and applications in soil fertility and carbon sequestration-a sustainable solution to crop-residue burning in India. RSC advances, 8(1), pp.508-520.

Stępień, P., Serowik, M., Koziel, J.A. and Białowiec, A., 2019. Waste to Carbon Energy Demand Model and Data Based on the TGA and DSC Analysis of Individual MSW Components. Data, 4(2), p.53.

Tan, R.R., Bandyopadhyay, S. and Foo, D.C., 2018. Graphical pinch analysis for planning biochar-based carbon management networks. Process Integration and Optimization for Sustainability, 2(3), pp.159-168.

Timmons, D., Lema-Driscoll, A. and Uddin, G., 2017. The economics of Biochar carbon sequestration in Massachusetts. University of Massachusetts, Boston. 
US Biochar Initiative, 2018, Survey and Analysis of the US Biochar Industry Survey and Analysis of the US Biochar Industry, WERC project MN17-DG-230 (https://biocharus.org/). [Accessed on 30-Aug-2019].

Vochozka, M., Maroušková, A., Váchal, J. and Straková, J., 2016. Biochar pricing hampers biochar farming. Clean technologies and environmental policy, 18(4), pp.1225-1231.

Wijitkosum, S. and Sriburi, T., 2018. Increasing the Amount of Biomass in Field Crops for Carbon Sequestration and Plant Biomass Enhancement Using Biochar. In Biochar-An Imperative Amendment for Soil and the Environment. IntechOpen, pp.1-13. 